Research Article

Check for updates
OPEN ACCESS

Received: May 7, 2019

Accepted: Sep 10, 2019

*Correspondence:

Soo Young Kim

Department of Occupational \& Environmental Medicine, Eulji University Hospital, 95 Dunsanseo-ro, Seo-gu, Daejeon 35233, Korea. E-mail: kimsooy@gmail.com

Copyright (c) 2019 Korean Society of Occupational \& Environmental Medicine This is an Open Access article distributed under the terms of the Creative Commons Attribution Non-Commercial License (https:// creativecommons.org/licenses/by-nc/4.0/) which permits unrestricted non-commercial use, distribution, and reproduction in any medium, provided the original work is properly cited.

ORCID iDs

Young Gon Choi (iD

https://orcid.org/0000-0001-8469-6014 Byung Jin Choi (D)

https://orcid.org/0000-0003-1325-0263 Tae Hwi Park (D)

https://orcid.org/0000-0002-1565-5988 Jun Young Uhm (iD)

https://orcid.org/0000-0003-3703-9681 Dong Bae Lee (D)

https://orcid.org/0000-0001-6177-0488 Seong Sil Chang (D)

https://orcid.org/0000-0003-1581-1378 Soo Young Kim (iD)

https://orcid.org/0000-0002-7760-7420

Abbreviations

ANCOVA: analysis of covariance; ANOVA:

analysis of variance; AUDIT-K: Korean version

\section{A study on the characteristics of Maslach Burnout Inventory-General Survey (MBI-GS) of workers in one electronics company}

\author{
Young Gon Choi $\mathbb{1}$, Byung Jin Choi $\mathbb{1}$, Tae Hwi Park $\mathbb{1}$, Jun Young Uhm (1),

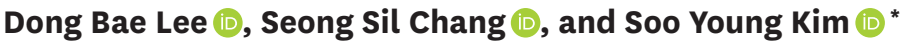

Department of Occupational \& Environmental Medicine, Eulji University Hospital, Daejeon, Korea 
of Alcohol Use Disorder Identification Test; BDI: Beck Depression Inventory; KOSS: Korean Occupational Stress Scale; KOSS-SF: Korean Occupational Stress Scale-Short Form; MBI: Maslach Burnout Inventory; MBI-ES: Maslach Burnout Inventory-Educators Survey; MBI-GS Maslach Burnout Inventory-General Survey; MBI-HSS: Maslach Burnout Inventory-Human Services Survey; OECD: Organization for Economic Co-operation and Development; PHQ-9: Patient Health Questionnaire-9; QOL: quality of life; WHOQOL-BREF: World Health Organization Quality Of Life-Abbreviated version

\section{Competing interests}

The authors declare that they have no competing interests.

Availability of data and materials

Please contact author for data requests.

Author contributions

Conceptualization: Choi YG. Data curation: Choi BJ, Park TH, Uhm JY. Formal analysis: Chang SS, Lee DB. Investigation: Choi BJ, Park TH, Uhm JY. Writing - original draft: Choi YG, Choi BJ, Park TH, Uhm JY. Writing - review \& editing: Kim SY

\section{BACKGROUND}

One of the common phrases we hear these days is "I'm totally burned out." It is an expression usually used when you are utterly tired of doing something or working, and when you need to take a break because it is hard to continue working anymore. One dictionary defines burnout as a "feeling of always being tired because you have been working too hard" [1]. As can be seen in the definition, burnout occurs when you work. Medically, burnout is defined as "a psychological syndrome of emotional exhaustion, depersonalization, and reduced personal accomplishment that can occur among individuals who work with other people in some capacity" [2]. It is also considered to be one of the long-term negative effects due to occupational stress or occupational fatigue $[3,4]$ and is considered to be a special type of occupational stress [5]. This burnout has an adverse effect not only from the organizational point of view but also on the physical as well as the psychological aspects of each individual. Studies have shown that burnout results in negative organizational effects such as decreased productivity, increased turnover, and increased absenteeism [6-8] has a high correlation with depression [9-12] and causes sleep disorder and deterioration in memory and attention $[13,14]$, leading the workers to feel that their subjective health is not good $[11,15,16]$. Burnout is also associated with the development of coronary heart disease and increases the risk of chronic diseases such as diabetes and musculoskeletal disorders [17,18]. It also triggers a negative lifestyle, such as smoking, drinking, and lack of physical activities [17,19] and lowers the quality of life (QOL) [20].

Because of these various negative effects, the importance of burnout has been gaining attention from people living and working in modern society, and Maslach Burnout Inventory (MBI) developed by Maslach et al. [2] is widely used as a tool to assess such burnout. The original MBI gradually evolved, and it is now categorized into 3 types, which are Maslach Burnout InventoryHuman Services Survey (MBI-HSS), Maslach Burnout Inventory-Educators Survey (MBI-ES), and Maslach Burnout Inventory-General Survey (MBI-GS), depending on the worker's job. In MBI-GS, which is used for the most general occupational group, the scale consists of 3 sub-scales; exhaustion, cynicism, and professional efficacy. "Exhaustion" means emotional and physical fatigue due to workloads, demands, etc. "Cynicism" means being indifferent or distancing oneself from the work or taking a negative attitude toward the work overall. "Professional efficacy" means satisfaction with one's past and present work achievements and expectations of continued effectiveness at work. Determination of burnout using MBI-GS is such that the higher the scores in the exhaustion and cynicism field and the lower the score in professional efficacy, the higher the degree of burnout is assessed to be [2]. The validity of the MBI-GS was verified in studies conducted in various European countries [21], and the validity of the MBI-GS was verified in Korea by Shin translating it into Korean [22].

However, since MBI-GS is not a scale made for disease diagnosis or screening purposes, no cutoff value is presented. In order to overcome this problem, research was conducted to determine the reference value of MBI by analyzing the population of Germany and the United States. The results showed that the score distribution of the MBI in the German and US populations differed from each other in sub-scales of MBI [23]. A comparison of past studies on burnout conducted on nurses showed similar MBI scores in Poland and North America, and the MBI scores in the UK and Ireland were lower than those in Poland and North America [24-27]. These differences are thought to have been caused by demographic differences and the difference in the work environment, the degree of stress, and occupational characteristics among countries. Therefore, in order to identify the degree of burnout through the MBI score 
in Korea, it is necessary to identify the distribution of the scores and its characteristics with the Korean population. However, although there are a few studies on the distribution and characteristics of MBI in Korea, as far as the author is aware, no studies have been conducted on reference values.

Therefore, the purpose of this study is to conduct MBI-GS, which covers the most general types of jobs, and to investigate characteristics according to demographic factors and occupational factors. In addition, the correlations between burnout and work stress, depression, and QOL, which are known to have a significant correlation with burnout are examined; MBI-GS scores by group for each factor are investigated; and the distribution of scores of sub-scales is presented by quartiles.

\section{METHODS}

\section{Study population}

This study was conducted from September 13, 2017, to December 15, 2017, for those working in electronics company. The survey was conducted on a total of 5,500 employees, out of whom 949 employees were in workplace A in Incheon, 743 employees were in workplace B, and 3,808 employees were in workplace $\mathrm{C}$ in Jeonnam Province. Excluding the participants who did not answer the items that needed to be investigated, participants who omitted some parts of answers, duplicated respondents, and those participants with illegible handwriting, a total of 3,331 people were selected as the subjects, consisting of 1,781 male and 1,550 female.

\section{Measurement tools}

MBI-GS

The measurement of the burnout was performed using a Korean version of MBI-GS, which is the Korean translation of MBI-GS developed by Maslach et al. [2]. The Korean version of MBI-GS was translated by Shin [22], and its validity was verified. It consisted of 5 questions on exhaustion, 4 on cynicism, and 6 on professional efficacy, making 15 questions in total. Each item is a self-reported questionnaire-type question made up of a 7-point scale (0-6 points). The degree of burnout is determined to be higher when the scores in exhaustion and cynicism are high, and the score in professional efficacy is low [2].

Korean Occupational Stress Scale-Short Form (KOSS-SF)

Occupational stress was measured using the Korean Occupational Stress Scale (KOSS) developed by Chang et al. [28] in Korea. The KOSS has been verifiably correlated with the Job Content Questionnaire, a commonly used occupational stress measurement tool overseas, and is the occupational stress measurement tool that was developed reflecting both the general and specific job-related stress factors of Korea as well as the country's organizational structure and cultural characteristics. The KOSS-Short Form is composed of 7 sub-scales with 24 questions selected from the full version: job demand, insufficient job control, interpersonal conflict, job insecurity, organizational system, lack of reward, and occupational climate. The questions are self-reported questionnaire-type questions consisting of a 4-point scale (1-4 points). The total score is calculated by summing up the scores of each sub-scale, and the higher the total score, the greater the occupational stress [28]. In this study, we used quartile reference values from previous studies [28] to classify the group with the lowest occupational stress as the first quartile, and the group with the most severe stress as the fourth quartile, in total classifying all the subjects into 4 groups. 
Patient Health Questionnaire-9 (PHQ-9)

Depression was measured using the Korean version of PHQ-9 originally developed by Kroenke and Spitzer [29]. For the Korean version of PHQ-9, Choi et al. [30] translated the original into Korean, and its validity was verified. The previous study results showed that the sensitivity and specificity were higher than the Korean version of the Beck Depression Inventory (BDI) [30]. PHQ-9 is commonly used as a screening test for depression. It consists of a total of 9 items, each of which is a self-reported question consisting of a 4-point scale ( $0-3$ points). The total score is calculated by summing up the scores of each item to determine depression severity [29]; none for 0-4 points, mild for 5-9 points, moderate to severe for more than 10 points.

\section{World Health Organization Quality of Life-Abbreviated version (WHOQOL-BREF)}

QOL was measured using the Korean version of WHOQOL-BREF originally developed by World Health Organization [31]. The Korean version WHOQOL-BREF was made by Min et al. [32] translating the original into Korean, and its validity was verified. WHOQOL-BREF is a measurement tool that is made by selecting 26 items from the full version. It contains questions on overall QOL and general health. It comprises the 4 domains of physical health, psychological health, social relationships, and environment. Each item is a self-reported questionnaire-type question consisting of a 5 -point scale ( $1-5$ points). The total score is calculated by summing up the scores of each item, and the higher the total score, the better the QOL [31]. In this study, we used counter-scoring for Pearson's correlation analysis and classify the best QOL as the first quartile and the worst QOL as the fourth quartile, classifying all the subjects into 4 groups in total.

\section{Demographic factors and occupational factors}

In addition to the measurement tools mentioned above, information on age, sex, marital status, regular leisure time, smoking status, problem drinking behavior, working type, working time, working duration, and working department was collected through questionnaires. Participants were classified by age as 29 or younger, 30-39 years old, 40-49 years old, and 50 or older, and classified by marital status as unmarried and married. Regular leisure life was classified as "Yes" if a leisure or hobby activity was regularly carried out for more than 30 minutes at a time and at least 2-3 times per week, and "No" if it was not. Participants were classified by smoking status into non-smoker, ex-smoker, and current smoker. According to the Korean version of Alcohol Use Disorder Identification Test (AUDIT-K) guidelines, problem drinking behaviors were classified as "Yes" for scores of 10 or higher for male and 6 or higher for female, and "No" for scores lower than those, respectively [33]. The working type was classified as fixed-day and shift or others, and working time was classified into 40 hours or less, 41-52 hours, and 53 hours or more by examining average working hours for a week including overtime or extra work. Working duration was classified as 12 months or less, 13-60 months, 61-120 months, and 121 months or longer by investigating the working duration of participants' current job. Working department was classified based on the seventh edition of Korean Standard Classification of Occupations [34] after the responses on "working department" were collected and checked. The occupational groups with less than $1 \%$ of respondents were classified as "Others."

\section{Statistical analyses}

The results for the total subjects and the results divided by sex are presented together. Cronbach's alpha value was calculated to evaluate the internal consistency of MBI-GS. And the scores of MBI-GS for each sub-scales and the mean value of total scores according to 
demographic factors and occupational factors were compared by t-test and one-way analysis of variance (ANOVA). And Bonferroni test and Dunnet's test were performed for post hoc analysis. In order to verify the concurrent validity of MBI-GS, the correlation was analyzed with KOSS-SF, PHQ-9, and WHOQOL-BREF respectively by Pearson correlation analysis. Analysis of covariance (ANCOVA) was performed to compare the mean of MBI-GS in the groups that categorized KOSS-SF, PHQ-9, and WHOQOL-BREF. Statistical significance was set as $p<0.05$, and statistical analysis was performed using SPSS ver. 18.0 (SPSS Inc., Chicago, IL, USA).

\section{Ethics statement}

Our study was approved by the Institutional Review Board of Eulji University Hospital (Approval No. EMC 2019-02-015).

\section{RESULTS}

\section{General characteristics of study population}

The general characteristics of the subjects are shown in Table 1 . The total number of subjects was 3,331, of which 1,781 were male and 1,550 were female. The average age of the total subjects was 35.3 years, with the average age of the male being 38.1 years, and the average age of the female being 32.2 years. For age distribution, the number of male was the highest in the 40-49 age group, and the number of female was highest in 29 or younger group. As for marital status, male was more likely to be married than female. In the lifestyle factors category, male had a higher rate of regular leisure time and were more likely to be current smokers than female, and problem drinking behavior was higher in female than in male. In the working type category, the rate of female belonging to shift lines or other types of work was higher than the number of male. In the working time category, the rate of female working less than 40 hours was higher than that of male. In the working duration category, the highest number was in the 13-60 months group among both male and female. According to the occupational classification, the largest occupational group for both male and female was elementary workers.

\section{Internal consistency}

The Cronbach's alpha value of MBI-GS is shown in Table 2. The Cronbach's alpha values of exhaustion, cynicism, and professional efficacy were $0.918,0.871$, and 0.893 , respectively, for all subjects. The values were $0.915,0.884$, and 0.898 for male, and $0.910,0.856$, and 0.869 for female, respectively.

\section{The comparison of mean values of MBI-GS (demographic and occupational} factors)

The mean score and statistical significance of MBI-GS according to demographic factors and occupational factors is shown in Table 3.

As a result of the comparison, in male, the mean score of exhaustion differed significantly according to age, problem drinking behavior, working time, and working duration, and the mean score of cynicism differed significantly according to working duration. The mean score of professional efficacy differed significantly according to age, marital status, working type, working duration and occupational distribution. Among female, the mean score of exhaustion differed significantly according to age, marital status, problem drinking behavior, 


\begin{tabular}{|c|c|c|c|}
\hline Variables & Total & Male & Female \\
\hline Total & 3,331 & 1,781 & 1,550 \\
\hline \multicolumn{4}{|l|}{ Age (years) } \\
\hline Mean \pm standard error & $35.3 \pm 8.7$ & $38.1 \pm 8.2$ & $32.2 \pm 8.2$ \\
\hline 29 or under & $959(28.8)$ & $321(18.0)$ & $638(41.2)$ \\
\hline $30-39$ & 1,255 (37.7) & $629(35.3)$ & $626(40.4)$ \\
\hline $40-49$ & $951(28.5)$ & $697(39.1)$ & $254(16.4)$ \\
\hline 50 or older & $168(5.0)$ & $134(7.5)$ & $32(2.1)$ \\
\hline \multicolumn{4}{|l|}{ Marital status } \\
\hline Unmarried & $1,426(42.8)$ & $563(31.6)$ & $863(55.7)$ \\
\hline Married & 1,905 (57.2) & $1,218(68.4)$ & $687(44.3)$ \\
\hline \multicolumn{4}{|l|}{ Regular leisure life } \\
\hline No & $2,056(61.7)$ & $792(44.5)$ & $1,264(81.5)$ \\
\hline Yes & $1,275(38.3)$ & $989(55.5)$ & $286(18.5)$ \\
\hline \multicolumn{4}{|l|}{ Smoking status } \\
\hline Non-smoker & $2,197(66.0)$ & $805(45.2)$ & 1,392 (89.8) \\
\hline Ex-smoker & 495 (14.9) & $429(24.1)$ & $66(4.3)$ \\
\hline Current smoker & $639(19.2)$ & $547(30.7)$ & $92(5.9)$ \\
\hline \multicolumn{4}{|l|}{ Problem drinking behavior } \\
\hline No & $1,771(53.2)$ & $1,023(57.4)$ & $748(48.3)$ \\
\hline Yes & $1,560(46.8)$ & $758(42.6)$ & 802 (51.7) \\
\hline \multicolumn{4}{|l|}{ Working type } \\
\hline Day fixed & $1,114(33.4)$ & $859(48.2)$ & $255(16.5)$ \\
\hline Shift or others & $2,217(66.6)$ & $922(51.8)$ & $1,295(83.5)$ \\
\hline \multicolumn{4}{|l|}{ Working time (hour/week) } \\
\hline$\leq 40$ & $2,476(74.3)$ & $1,218(68.4)$ & $1,258(81.2)$ \\
\hline $41-52$ & $750(22.5)$ & $477(26.8)$ & $273(17.6)$ \\
\hline$\geq 53$ & $105(3.2)$ & $86(4.8)$ & $19(1.2)$ \\
\hline \multicolumn{4}{|l|}{ Working duration (month) } \\
\hline$\leq 12$ & $639(19.2)$ & $299(16.8)$ & $340(21.9)$ \\
\hline $13-60$ & $1,045(31.4)$ & $569(31.9)$ & $476(30.7)$ \\
\hline $61-120$ & $707(21.2)$ & 365 (20.5) & $342(22.1)$ \\
\hline$\geq 121$ & $940(28.2)$ & $548(30.8)$ & $392(25.2)$ \\
\hline \multicolumn{4}{|l|}{ Occupational distribution } \\
\hline Elementary workers & $2,131(64.0)$ & $970(54.5)$ & $1,161(74.9)$ \\
\hline Professionals and related workers & $513(15.4)$ & $411(23.1)$ & $102(6.6)$ \\
\hline Clerks & $179(5.4)$ & $125(7.0)$ & $54(3.5)$ \\
\hline Managers & $173(5.2)$ & $57(3.2)$ & $116(7.5)$ \\
\hline Craft and related trades workers & $163(4.9)$ & $131(7.4)$ & $32(2.1)$ \\
\hline $\begin{array}{l}\text { Equipment, machine operating and assembling } \\
\text { workers }\end{array}$ & $118(3.5)$ & $64(3.6)$ & $54(3.5)$ \\
\hline Others & $54(1.6)$ & $23(1.3)$ & $31(2.0)$ \\
\hline
\end{tabular}

Values are presented as number (\%).

Table 2. Cronbach's alpha value of MBI-GS and its sub-scales

\begin{tabular}{lllc}
\hline Sub-scales & Total & Male & Female \\
\hline Exhaustion & 0.918 & 0.915 & 0.910 \\
Cynicism & 0.871 & 0.884 & 0.856 \\
Professional efficacy & 0.893 & 0.898 & 0.869 \\
\hline
\end{tabular}

MBI-GS: Maslach Burnout Inventory-General Survey.

working type, working time, and working duration, and the mean score of cynicism differed significantly according to age, marital status, problem drinking behavior, and working time. The score value of professional efficacy differed significantly according to age, marital status, working type, working duration, and occupational distribution.

In case of post hoc analyses in male, the mean scores of exhaustion of 30s and 40s age group are lower than 50 or older. And the mean score of professional efficacy of 29 or under age 
Table 3. Mean scores of MBI-GS and its sub-scales according to demographic and occupational factors

\begin{tabular}{|c|c|c|c|c|c|c|}
\hline \multirow[t]{2}{*}{ Variables } & \multicolumn{2}{|c|}{ Exhaustion } & \multicolumn{2}{|c|}{ Cynicism } & \multicolumn{2}{|c|}{ Professional efficacy } \\
\hline & Male & Female & Male & Female & Male & Female \\
\hline Sex & $17.1 \pm 6.5^{\mathrm{a}}$ & $21.0 \pm 7.1$ & $10.5 \pm 4.7^{a}$ & $11.7 \pm 5.0$ & $29.1 \pm 6.1^{a}$ & $25.4 \pm 6.1$ \\
\hline \multicolumn{7}{|l|}{ Age (years) } \\
\hline 29 or younger & $16.5 \pm 6.9^{\mathrm{a}}$ & $21.6 \pm 6.7^{\mathrm{a}, 1}$ & $10.2 \pm 4.8$ & $12.1 \pm 4.8^{\mathrm{a}}$ & $27.0 \pm 5.9^{\mathrm{a}, 1}$ & $23.9 \pm 5.6^{\mathrm{a},}$ \\
\hline $30-39$ & $17.7 \pm 6.3^{1}$ & $21.1 \pm 7.2$ & $10.7 \pm 4.6$ & $11.8 \pm 5.2$ & $28.8 \pm 5.7^{2}$ & $25.9 \pm 5.8^{2}$ \\
\hline $40-49$ & $17.1 \pm 6.3^{1}$ & $19.2 \pm 7.6^{2}$ & $10.3 \pm 4.8$ & $10.1 \pm 5.0$ & $30.3 \pm 6.1^{2}$ & $27.8 \pm 6.9^{2}$ \\
\hline 50 or older & $15.2 \pm 6.5^{2}$ & $18.1 \pm 6.5^{2}$ & $10.4 \pm 5.1$ & $11.0 \pm 4.7$ & $29.3 \pm 7.2^{2}$ & $25.8 \pm 6.3^{2}$ \\
\hline \multicolumn{7}{|l|}{ Marital status } \\
\hline Unmarried & $17.1 \pm 7.0$ & $21.3 \pm 7.0^{a}$ & $10.7 \pm 5.0$ & $12.1 \pm 5.0^{a}$ & $27.4 \pm 6.0^{\mathrm{a}}$ & $24.2 \pm 5.8^{a}$ \\
\hline Married & $17.1 \pm 6.2$ & $20.5 \pm 7.3$ & $10.4 \pm 4.6$ & $11.4 \pm 5.1$ & $30.0 \pm 6.0$ & $26.9 \pm 6.1$ \\
\hline \multicolumn{7}{|l|}{ Regular leisure life } \\
\hline No & $17.3 \pm 6.4$ & $21.0 \pm 7.2$ & $10.7 \pm 4.8$ & $11.8 \pm 5.1$ & $28.9 \pm 6.0$ & $25.3 \pm 6.1$ \\
\hline Yes & $16.9 \pm 6.5$ & $20.5 \pm 6.9$ & $16.9 \pm 6.5$ & $11.6 \pm 4.9$ & $29.2 \pm 6.2$ & $25.6 \pm 6.2$ \\
\hline \multicolumn{7}{|l|}{ Smoking status } \\
\hline Non-smoker & $17.1 \pm 6.4$ & $20.9 \pm 7.1$ & $10.5 \pm 4.7$ & $11.7 \pm 5.0$ & $29.0 \pm 6.1$ & $25.5 \pm 6.2$ \\
\hline Ex-smoker & $17.2 \pm 6.4$ & $22.1 \pm 6.7$ & $10.6 \pm 4.9$ & $11.6 \pm 4.9$ & $29.7 \pm 6.2$ & $25.2 \pm 5.9$ \\
\hline Current smoker & $16.9 \pm 6.6$ & $21.5 \pm 7.3$ & $10.4 \pm 4.7$ & $12.2 \pm 5.1$ & $28.8 \pm 6.0$ & $24.3 \pm 5.5$ \\
\hline \multicolumn{7}{|l|}{ Problem drinking behavior } \\
\hline No & $16.6 \pm 6.5^{a}$ & $20.5 \pm 7.3^{a}$ & $10.3 \pm 4.8$ & $11.5 \pm 5.1^{\mathrm{a}}$ & $29.2 \pm 6.3$ & $25.6 \pm 6.2$ \\
\hline Yes & $17.7 \pm 6.4$ & $21.4 \pm 7.0$ & $10.7 \pm 4.6$ & $12.0 \pm 4.9$ & $29.0 \pm 5.9$ & $25.2 \pm 6.0$ \\
\hline \multicolumn{7}{|l|}{ Working type } \\
\hline Day fixed & $17.2 \pm 6.4$ & $20.0 \pm 7.3^{a}$ & $10.4 \pm 4.7$ & $11.7 \pm 5.0$ & $29.8 \pm 6.1^{a}$ & $27.9 \pm 6.0^{a}$ \\
\hline Shift or others & $17.0 \pm 6.6$ & $21.1 \pm 7.1$ & $10.6 \pm 4.8$ & $11.8 \pm 5.2$ & $28.4 \pm 6.1$ & $24.9 \pm 6.0$ \\
\hline \multicolumn{7}{|l|}{ Working time (hour/week) } \\
\hline$\leq 40$ & $16.5 \pm 6.4^{\mathrm{a}, 1}$ & $20.6 \pm 7.2^{\mathrm{a}, 2}$ & $10.3 \pm 4.8$ & $11.5 \pm 5.0^{\mathrm{a}, 2}$ & $28.9 \pm 6.1$ & $25.3 \pm 6.1$ \\
\hline $41-52$ & $17.9 \pm 6.3^{2}$ & $22.6 \pm 6.6^{2}$ & $10.7 \pm 4.6$ & $12.7 \pm 5.0^{2}$ & $29.2 \pm 6.3$ & $25.6 \pm 6.2$ \\
\hline$\geq 53$ & $20.5 \pm 6.7^{3}$ & $22.5 \pm 7.1$ & $11.4 \pm 4.8$ & $13.0 \pm 4.2$ & $30.4 \pm 6.1$ & $26.5 \pm 5.5$ \\
\hline \multicolumn{7}{|l|}{ Working duration (month) } \\
\hline$\leq 12$ & $15.8 \pm 6.7^{\mathrm{a}, 1}$ & $20.9 \pm 7.0^{\mathrm{a}}$ & $9.7 \pm 4.6^{\mathrm{a}}$ & $12.0 \pm 4.8$ & $27.7 \pm 6.0^{\mathrm{a}, 1}$ & $23.7 \pm 5.5^{\mathrm{a}, 1}$ \\
\hline $13-60$ & $17.4 \pm 6.7^{2}$ & $21.4 \pm 7.4$ & $10.7 \pm 5.0$ & $11.8 \pm 5.4$ & $28.6 \pm 6.1^{2}$ & $25.1 \pm 6.3^{2}$ \\
\hline $61-120$ & $17.5 \pm 6.1^{2}$ & $21.5 \pm 6.9^{1}$ & $10.9 \pm 4.5$ & $11.9 \pm 4.7$ & $29.1 \pm 6.2^{2}$ & $26.0 \pm 5.9^{2}$ \\
\hline$\geq 121$ & $17.2 \pm 6.3^{2}$ & $20.0 \pm 7.1^{2}$ & $10.4 \pm 4.7$ & $11.4 \pm 5.0$ & $30.3 \pm 5.9^{2}$ & $26.7 \pm 6.2^{2}$ \\
\hline \multicolumn{7}{|l|}{ Occupational distribution } \\
\hline Elementary workers & $17.0 \pm 6.5$ & $21.0 \pm 7.2$ & $10.6 \pm 4.9$ & $11.6 \pm 5.0$ & $28.6 \pm 6.1^{\mathrm{a}, 1}$ & $25.2 \pm 6.1^{\mathrm{a}, 1}$ \\
\hline Professionals and related workers & $16.6 \pm 6.5$ & $21.7 \pm 6.5$ & $10.1 \pm 4.5$ & $12.8 \pm 5.9$ & $29.6 \pm 6.5$ & $26.3 \pm 6.5$ \\
\hline Clerks & $17.1 \pm 6.2$ & $21.0 \pm 6.8$ & $10.1 \pm 4.7$ & $12.6 \pm 4.9$ & $29.7 \pm 5.9^{2}$ & $25.5 \pm 5.3$ \\
\hline Managers & $17.5 \pm 6.7$ & $19.2 \pm 7.6$ & $10.7 \pm 4.6$ & $10.5 \pm 5.2$ & $29.3 \pm 5.9$ & $27.7 \pm 7.1$ \\
\hline Craft and related trades workers & $17.0 \pm 7.2$ & $19.8 \pm 7.5$ & $10.0 \pm 4.8$ & $11.4 \pm 5.2$ & $30.7 \pm 6.5$ & $28.6 \pm 7.1^{2}$ \\
\hline Equipment, machine operating and assembling workers & $18.3 \pm 6.0$ & $20.7 \pm 6.7$ & $10.5 \pm 3.9$ & $12.2 \pm 4.8$ & $30.1 \pm 5.9$ & $24.7 \pm 5.3^{1,3}$ \\
\hline Others & $17.8 \pm 7.1$ & $24.1 \pm 7.6$ & $11.0 \pm 4.8$ & $12.5 \pm 4.3$ & $28.4 \pm 8.3$ & $26.7 \pm 6.4$ \\
\hline Total & \multicolumn{2}{|c|}{$18.9 \pm 7.1$} & \multicolumn{2}{|c|}{$11.1 \pm 4.9$} & \multicolumn{2}{|c|}{$27.4 \pm 6.4$} \\
\hline
\end{tabular}

Values are presented as mean \pm standard deviation.

MBI-GS: Maslach Burnout Inventory-General Survey.

${ }^{a}$ The $p$-value $<0.05$, calculated by t-test or analysis of variance; ${ }^{1,2,3}$ Significant differences in post hoc analysis if mean scores have different number in same factors.

group is lower than every other age group. The mean score of exhaustion differed in each group according to working time. In working duration, 12 month or less is lower than every other group in exhaustion and professional efficacy. And mean score of professional efficacy showed significant difference between elementary workers and clerks. Among female, the mean score of exhaustion of 40s and 50 or older age group are lower than 29 or under. And the results of professional efficacy according to age showed the same results of male. In working time, significant difference showed between 40 or less and 41-52 in exhaustion and cynicism. The mean score of exhaustion of working duration showed significant difference between 61-120 months group and 121 or longer. And the result of professional efficacy according to working duration is as same as male's. And mean score of professional efficacy 
Table 4. Correlation coefficient between sub-scales of MBI-GS and other scales ${ }^{\mathrm{a}}$

\begin{tabular}{|c|c|c|c|c|c|c|c|c|c|}
\hline \multirow[t]{2}{*}{ Scales } & \multicolumn{3}{|c|}{ Total } & \multicolumn{3}{|c|}{ Male } & \multicolumn{3}{|c|}{ Female } \\
\hline & Exhaustion & Cynicism & $\begin{array}{c}\text { Professional } \\
\text { efficacy }\end{array}$ & Exhaustion & Cynicism & $\begin{array}{c}\text { Professional } \\
\text { efficacy }\end{array}$ & Exhaustion & Cynicism & $\begin{array}{c}\text { Professional } \\
\text { efficacy }\end{array}$ \\
\hline KOSS-SF & 0.545 & 0.507 & -0.249 & 0.518 & 0.565 & -0.241 & 0.504 & 0.415 & -0.122 \\
\hline PHQ-9 & 0.592 & 0.484 & -0.244 & 0.566 & 0.502 & -0.213 & 0.561 & 0.441 & -0.160 \\
\hline WHOQOL-BREF & 0.504 & 0.464 & -0.307 & 0.506 & 0.476 & -0.256 & 0.445 & 0.425 & $-0.278^{*}$ \\
\hline
\end{tabular}

MBI-GS: Maslach Burnout Inventory-General Survey; KOSS-SF: Korean Occupational Stress Scale-Short Form; PHQ-9: Patient Health Questionnaire-9; WHOQOLBREF: World Health Organization Quality Of Life-Abbreviated version.

*The $p$-value $<0.05$, calculated by Pearson's correlation analysis.

showed significant difference between elementary workers and craft and related trades workers and between craft and related trades workers and equipment, machine operating, and assembling workers.

\section{Concurrent validity}

In order to analyze the concurrent validity, the correlation coefficient was analyzed by Pearson correlation analysis, and the result was presented in Table 4. All the correlation coefficients were statistically significant. Pearson correlation analysis was performed by setting continuous variables without categorizing scores of all variables. The correlation coefficient between exhaustion and PHQ-9 was the highest regardless of sex and the correlation coefficient of professional efficacy was the lowest in every scales.

\section{Comparison of mean scores of MBI-GS (KOSS-SF, PHQ-9, WHOQOL-BREF)}

The mean of MBI-GS was calculated for each group of KOSS-SF, PHQ-9, and WHOQOLBREF and presented in Tables 5-7 respectively. Each group was categorized according to the criteria described above in Methods section. ANCOVA adjusted for age, working time, working duration showed a statistically significant difference in all groups as a result of comparing mean scores for each group.

In the mean score for each group of KOSS-SF, for the groups with higher occupational stress, the mean scores of exhaustion and cynicism tended to increase for both male and female, while the mean score of professional efficacy tended to decrease (Table 5).

The mean score of PHQ-9 for each group showed that for both male and female, the mean score of exhaustion and cynicism tended to increase, while that for professional efficacy decreased going from none to mild and to moderate to severe (Table 6).

Table 5. Mean scores of MBI-GS and its sub-scales according to occupational stress (KOSS-SF)

\begin{tabular}{lrrrrr}
\hline Sub-scales & \multicolumn{5}{c}{ Occupational stress } \\
\cline { 2 - 6 } & 1st quartile & 2nd quartile & 3nd quartile & 4th quartile & $p$-value \\
\hline Male & & & & & \\
$\quad$ Exhaustion & $13.8 \pm 5.7$ & $18.0 \pm 5.3$ & $18.8 \pm 6.1$ & $22.2 \pm 5.8$ & $<0.001$ \\
$\quad$ Cynicism & $8.02 \pm 3.7$ & $10.5 \pm 4.1$ & $12.2 \pm 4.1$ & $14.8 \pm 4.9$ & $<0.001$ \\
$\quad$ Professional efficacy & $30.6 \pm 6.0$ & $28.7 \pm 5.5$ & $27.9 \pm 6.3$ & $27.1 \pm 6.3$ & $<0.001$ \\
Female & & & & & \\
$\quad$ Exhaustion & $16.4 \pm 6.9$ & $19.7 \pm 5.8$ & $22.3 \pm 6.3$ & $25.3 \pm 6.1$ & $<0.001$ \\
$\quad$ Cynicism & $9.1 \pm 4.5$ & $11.1 \pm 4.5$ & $12.5 \pm 4.5$ & $14.2 \pm 5.0$ & $<0.001$ \\
$\quad$ Professional efficacy & $26.7 \pm 6.2$ & $25.4 \pm 6.3$ & $24.3 \pm 5.3$ & $24.9 \pm 6.3$ & $<0.001$
\end{tabular}

The $p$-value: $p$-value of analysis of covariance (adjusted for age, working time, working duration).

MBI-GS: Maslach Burnout Inventory-General Survey; KOSS-SF: Korean Occupational Stress Scale-Short Form. 
Table 6. Mean scores of MBI-GS and its sub-scales according to personal mood (PHQ-9)

\begin{tabular}{|c|c|c|c|c|}
\hline \multirow[t]{2}{*}{ Sub-scales } & \multicolumn{4}{|c|}{ Depression severity } \\
\hline & None & Mild & Moderate to severe & $p$-value \\
\hline \multicolumn{5}{|l|}{ Total } \\
\hline Exhaustion & $15.3 \pm 6.1$ & $21.1 \pm 5.6$ & $25.8 \pm 5.7$ & $<0.001$ \\
\hline Cynicism & $9.1 \pm 4.3$ & $12.3 \pm 4.3$ & $15.0 \pm 4.8$ & $<0.001$ \\
\hline Professional efficacy & $28.8 \pm 6.4$ & $26.5 \pm 5.9$ & $24.9 \pm 6.2$ & $<0.001$ \\
\hline \multicolumn{5}{|l|}{ Male } \\
\hline Exhaustion & $14.6 \pm 5.7$ & $19.9 \pm 5.3$ & $24.3 \pm 5.4$ & $<0.001$ \\
\hline Cynicism & $8.9 \pm 4.1$ & $12.3 \pm 4.1$ & $15.1 \pm 5.3$ & $<0.001$ \\
\hline Professional efficacy & $30.0 \pm 6.1$ & $28.1 \pm 5.6$ & $26.6 \pm 6.3$ & $<0.001$ \\
\hline \multicolumn{5}{|l|}{ Female } \\
\hline Exhaustion & $16.6 \pm 6.5$ & $22.1 \pm 5.8$ & $26.5 \pm 5.7$ & $<0.001$ \\
\hline Cynicism & $9.4 \pm 4.6$ & $12.3 \pm 4.5$ & $14.9 \pm 4.6$ & $<0.001$ \\
\hline Professional efficacy & $26.5 \pm 6.4$ & $25.1 \pm 5.8$ & $24.0 \pm 5.9$ & $<0.001$ \\
\hline
\end{tabular}

The $p$-value: $p$-value of analysis of covariance (adjusted for age, working time, working duration). MBI-GS: Maslach Burnout Inventory-General Survey; PHQ-9: Patient Health Questionnaire-9.

Table 7. Mean scores of MBI-GS and its sub-scales according to Quality of life (WHOQOL-BREF)

\begin{tabular}{|c|c|c|c|c|c|}
\hline \multirow[t]{2}{*}{ Sub-scales } & \multicolumn{5}{|c|}{ Quality of life } \\
\hline & 1st quartile & 2nd quartile & 3nd quartile & 4th quartile & $p$-value \\
\hline \multicolumn{6}{|l|}{ Total } \\
\hline Exhaustion & $14.0 \pm 6.3$ & $17.8 \pm 6.3$ & $20.0 \pm 5.9$ & $23.0 \pm 6.2$ & $<0.001$ \\
\hline Cynicism & $8.0 \pm 4.0$ & $10.3 \pm 4.5$ & $11.8 \pm 4.3$ & $13.8 \pm 4.8$ & $<0.001$ \\
\hline Professional efficacy & $30.4 \pm 6.7$ & $27.5 \pm 5.8$ & $26.6 \pm 5.6$ & $25.3 \pm 6.4$ & $<0.001$ \\
\hline \multicolumn{6}{|l|}{ Male } \\
\hline Exhaustion & $12.7 \pm 5.7$ & $16.1 \pm 5.9$ & $17.7 \pm 5.7$ & $21.1 \pm 5.6$ & $<0.001$ \\
\hline Cynicism & $7.6 \pm 3.8$ & $9.5 \pm 4.2$ & $11.0 \pm 4.2$ & $13.4 \pm 4.6$ & $<0.001$ \\
\hline Professional efficacy & $31.5 \pm 6.6$ & $29.5 \pm 5.8$ & $28.5 \pm 5.6$ & $27.4 \pm 6.0$ & $<0.001$ \\
\hline \multicolumn{6}{|l|}{ Female } \\
\hline Exhaustion & $16.4 \pm 7.0$ & $19.7 \pm 6.7$ & $22.4 \pm 6.1$ & $24.5 \pm 6.2$ & $<0.001$ \\
\hline Cynicism & $8.7 \pm 4.4$ & $10.9 \pm 4.7$ & $12.5 \pm 4.5$ & $14.4 \pm 4.7$ & $<0.001$ \\
\hline Professional efficacy & $27.9 \pm 6.6$ & $25.3 \pm 5.2$ & $24.9 \pm 5.8$ & $23.6 \pm 6.0$ & $<0.001$ \\
\hline
\end{tabular}

The $p$-value: $p$-value of analysis of covariance (adjusted for age, working time, working duration).

MBI-GS: Maslach Burnout Inventory-General Survey; WHOQOL-BREF: World Health Organization Quality Of LifeAbbreviated version.

The mean score of WHOQOL-BREF for each group showed that for both male and female, the lower the QOL, the higher the mean score of exhaustion and cynicism tended to be and the lower the mean score of professional efficacy tended to be (Table 7).

\section{Quartile of MBI-GS and its sub-scales}

For the subjects of this study, the quartiles of each sub-scale of MBI-GS were divided according to male and female presented in Table 8. Female in the same quartile tended toward higher exhaustion and cynicism scores and lower scores in professional efficacy than male.

Table 8. Quartile of MBI-GS's sub-scale

\begin{tabular}{|c|c|c|c|c|}
\hline Sub-scales & $\mathrm{Q}_{-.24}$ & $\mathrm{Q}_{.25-49}$ & $\mathrm{Q}_{.50-.74}$ & $\mathrm{Q}_{\text {.75- }}$ \\
\hline \multicolumn{5}{|l|}{ Male } \\
\hline Exhaustion & $\leq 12$ & $13-18$ & $19-22$ & $\geq 23$ \\
\hline Cynicism & $\leq 7$ & $8-10$ & $11-14$ & $\geq 15$ \\
\hline Professional efficacy & $\geq 35$ & $30-34$ & $25-29$ & $\leq 24$ \\
\hline \multicolumn{5}{|l|}{ Female } \\
\hline Exhaustion & $\leq 16$ & $17-21$ & $22-26$ & $\geq 27$ \\
\hline Cynicism & $\leq 8$ & $9-12$ & $13-16$ & $\geq 17$ \\
\hline Professional efficacy & $\geq 30$ & $26-29$ & $23-25$ & $\leq 22$ \\
\hline
\end{tabular}

Q: quartile. 


\section{DISCUSSION}

The purposes of this study are first, to investigate the characteristics of MBI-GS according to demographic factors and occupational factors, second, to identify the correlation with factors known to be burnout-related and the MBI-GS score of each group, third, to identify the distribution of scores of each sub-scales by quartiles.

The Cronbach's alpha values of MBI-GS in this study were $0.915,0.884$, and 0.898 for exhaustion, cynicism, and professional efficacy, respectively, for male, and 0.910, 0.856, and 0.808 , respectively, for female. When the result was not divided by sex, they were 0.918 , 0.871 , and 0.893 , respectively (Table 2). The MBI-GS validation study, which was previously conducted by Shin in Korea [22], showed Cronbach's alpha values of $0.90,0.81$, and 0.86 for exhaustion, cynicism, and professional efficacy, respectively. A study of MBI-GS and health status by Choi [11], another study conducted in Korea, showed Cronbach's alpha values of $0.856,0.814$, and 0.883 for exhaustion, cynicism, and professional efficacy, respectively. In addition, the MBI-GS validity study by Schutte et al. [21], a study conducted abroad, showed a Cronbach's alpha value of $0.66-0.86$ for each sub-scale. Compared with previous studies in Korea and abroad, MBI-GS used in this study can be said to have a high internal consistency.

When the mean score of MBI-GS was compared according to demographic factors and occupational factors, the results differed by sex (Table 3). The factors that showed a significant difference in mean scores regardless of sex were age, problem drinking behavior, working time, and working duration in the exhaustion, and age, marital status, working type, and working duration in the professional efficacy. As you can see from the study results, the factors affecting the burnout vary by sex, and the affected sub-scales are also different. There are many studies about factors affecting the burnout like this study. But not every study shows the same results. Previous studies on factors affecting burnout have shown various contradictory results. Maslach et al. [3], who developed MBI-GS, suggested that these different research results are explained by the fact that social factors play a bigger role in the burnout than individual factors. In other words, people with the same conditions may have different degrees of burnout depending on the country in which they live or their workplaces.

First, the results of ANOVA and post hoc analysis on demographic factors in this study showed that exhaustion score was lower among male in the 50 or older age group than among male in their 30s or 40s, whereas in female, exhaustion score was lower in the 40s and 50 or older than in the 29 or younger age groups. This is thought to be a reflection of the social characteristics of Korea. In Korea, male tend to have higher incomes and greater needs for promotion than female. Year 2018 statistics show a female's employment rate of $57.2 \%$, ranking Korea 28th out of 36 Organization for Economic Co-operation and Development (OECD) member countries [35], and the sex wage gap in Korea was the worst among OECD member countries [36]. This indicates that in a typical Korean household, male tend to provide the main source of income, which explains the needs described above. And according to a survey by the Korea Research Institute for Vocational Education and Training, new employees in the manufacturing industry will be promoted to manager-level positions in 8.3-8.4 years, taking another 7.6-8.8 years to advance from a manager to a director level, and another 5.9-6.0 years from a director level to an executive level [37]. Therefore, when promotions are determined, those in their 30s and 40s feel a huge emotional burden, which results in higher scores for exhaustion compared to 50 or older. When they are in their 50 or older, they have a higher position in the company, the work volume reduces, and they 
have more feeling of security and familiarity with the workplace, leading to lower scores for exhaustion. On the other hand, considering the social characteristics of Korea that the employment rate of female is lower and the household burden of middle-aged female is greater than male, survival bias - i.e., female with a higher degree of burnout resign at an early age because of childbirth or child raising — can be a reason why degree of burnout is not higher among those in their 40s and 50s than among those in the 29 or younger group.

In professional efficacy, for both male and female, every other age groups shows higher scores than 29 or younger age group in post hoc analysis. It can be thought that as they work for a longer period, they become more familiarized with work. In the analysis result on marital status, married male had significantly higher scores in professional efficacy than unmarried male. And unmarried female had higher scores for exhaustion and cynicism and lower scores for professional efficacy. In other words, both unmarried male and female showed a higher degree of burnout, and such results are shown to be relatively consistent among various studies on burnout as suggested by Maslach et al. [3].

Although previous studies have reported that burnout leads to a negative lifestyle $[17,19]$ and problem drinking behavior was significant in some groups in this study, regular leisure activities and smoking status did not significantly affect the degree of burnout. Those results are thought to be that categorizations of life styles were too simple. Analysis of burnout by sex showed that the degree of burnout was significantly higher among female in all sub-scales. Considering the existing ideas of occupational stress being the key reason for burnout, it can be thought that female have more occupational stress than male. The development and standardization research on KOSS showed similar results. In the reference values presented by development and standardization research on KOSS, in the case of the same quartile, female tended to show higher KOSS scores than male [27]. In addition, results from previous studies reporting that female are more vulnerable to stress than male support the result of the present study [38-40].

The results of the occupational factors showed significant differences in professional efficacy in the case of working type. The day-fixed worker showed higher professional efficacy than the shift or other worker regardless of sex. And exhaustion score of day-fixed worker was higher than shift or other worker only in female. In working time, exhaustion score showed significant differences in every group for male in post hoc analysis. As working time increased, exhaustion score also increased. And female showed significant differences between 40 or less group and 41-50 group in exhaustion score and cynicism score in post hoc analysis. Both male and female showed no significant difference in professional efficacy. In working duration, statistically significant scores of each sub-scale were lower in the 12 months or less group only except exhaustion score of female in post hoc analysis. This is probably affected by the age distribution of each group. According to the analysis, the age distribution of the groups with a working duration of 12 months or less was $48.7 \%, 26.1 \%$, $18.5 \%$, and $6.7 \%$, respectively in the given order of age group, and as shown above, burnout is not as severe in the 29 or under age group as among those in their 30s or 40s in male. But female showed higher exhaustion score in 29 or under age group and that's the reason why there is different result only in exhaustion score of female in working duration. And workers in the 12 months or less working duration group are expected to have a relatively low sense of responsibility and pressure because of the distribution of workers in the job placement, takeover, and training process. The low score for professional efficacy is also explained by the fact that workers in the job placement, takeover, and training courses are not yet proficient 
at their work. In the occupational distribution category, there was a significant difference in professional efficacy regardless of sex. For male, professional efficacy score showed significant difference only between elementary workers and clerks in post hoc analysis. For female, professional efficacy score showed significant differences between elementary workers and craft and related trades workers and between craft and related trades workers and equipment, machine operating, and assembling workers in post hoc analysis. In previous abroad studies, it has been reported that blue-collar workers showed higher levels of cynicism and lower levels of professional efficacy than white-collar workers [21], but there was no remarkable result in this study maybe because categorization of occupation group is too specific and distribution of occupation is too uneven. It is thought that further investigation may be required for studying burnout by each occupation group.

Mean scores ( \pm standard deviation) were $18.9( \pm 7.1), 11.1( \pm 4.9)$, and $27.4( \pm 6.4)$ for exhaustion, cynicism, and professional efficacy, respectively (Table 3), when calculated without differentiating between sex or factors. In the results of abroad studies, the mean of the MBI-GS for each sub-scales in the Finnish population was $7.6( \pm 7.0), 4.9( \pm 6.1)$, and $23.4( \pm 10.1)$ [21] , and $9.7( \pm 7.1), 6.7( \pm 5.3)$, and $28.2( \pm 5.5)$ for the Norwegian population [41]. For Germans, the results were $11.5( \pm 6.8), 7.6( \pm 5.0)$, and 25.3 ( \pm 5.3$)$, and for the Greek population, $16.0( \pm 7.4), 12.0( \pm 5.7)$, and $28.9( \pm 6.4)$ [42]. If the results of the present study are compared with the results of the above abroad studies, Koreans have a higher level of exhaustion and cynicism than the Finnish, Norwegian, and German populations and similar levels to the Greek population. Scores for professional efficacy were higher in Korea than in Finland and Germany, but lower than those of Norway and Greece. In particular, when compared with Norwegians, Koreans had higher scores for exhaustion and cynicism but lower scores for professional efficacy. In the case of Greece, their scores were higher in exhaustion and cynicism than those of Finland, Norway, and Germany, and the scores were actually similar to Korea's. The reason for these different results even within Europe is that, since the research in Greece was published in 2012, it reflects the impact of the Greek financial crisis in 2010. In the study conducted in China, belonging to the Asian region, the mean was $7.2( \pm 5.5), 3.6( \pm 4.3)$, and $24.4( \pm 10.8)$, respectively [43]. Compared with all the results from abroad, it can be seen that exhaustion and cynicism tend to be severe in Korea.

In order to verify the concurrent validity of MBI-GS, we used 3 factors that were found to be significantly related to burnout in domestic and abroad studies (Table 4). Correlation coefficients respectively calculated from the correlation analysis ranged from -0.122 to 0.592 . The lowest correlation coefficient was obtained in the correlation analysis of professional efficacy and occupational stress in female $(\mathrm{r}=-0.122)$, and the highest correlation coefficient was obtained in the correlation analysis of exhaustion and depression in total $(\mathrm{r}=0.592)$. In the previous studies, Wu et al.'s research [44] on burnout and occupational stress showed that, as a result of correlation analysis between each sub-scale of MBI and each field of occupational stress inventory (role overload, role insufficiency, role ambiguity, role boundary, etc.) the correlation coefficients were in the range of 0.197-0.418. In addition, in research on police officers, Rothmann [45] showed a correlation coefficient of 0.17-0.28 as a result of correlation analysis between each sub-scale of the MBI and that of the Police Stress Inventory. The correlation coefficients between sub-scales of MBI-GS and KOSS-SF analyzed in this study were $-0.122-0.565$. In Valente et al.'s study [46] of burnout and depression, correlation analysis of each sub-scale of MBI with PHQ-9 showed a correlation coefficient of 0.28-0.59. In addition, the correlation coefficient with MBI was 0.27-0.44 when the BDI was used as a measure of depression $[47,48]$. The correlation coefficients between sub-scales 
of MBI-GS and PHQ-9 analyzed in this study were -0.160-0.592. In addition, in Aytekin et al.'s research [49], the correlation analysis of each sub-scale of MBI and that of WHOQOLBREF demonstrated a correlation coefficient of 0.283-0.570. In the study using Health Related Quality of Life as a measure of QOL, the correlation coefficient was 0.222-0.537 [50]. The correlation coefficients between MBI-GS and WHOQOL-BREF in this study were $-0.256-0.506$. Comparing results of this study with other results, correlation coefficients of professional efficacy of this study tend to similar or lower than other studies and correlation coefficients of exhaustion and cynicism tend to higher than other studies. As a result, in this study population, professional efficacy was the least correlated with other scales. It is thought that this result came from occupational distribution of study population. The largest proportion of occupational distribution is elementary worker in this study. Elementary worker usually perform the same tasks repeatedly and are likely to get used to them. It is thought that's the reason why there is relatively small difference in score of professional efficacy and result in the least correlation.

When the mean of MBI-GS was compared after categorizing KOSS-SF, PHQ-9, and WHOQOL-BREF, the mean value of MBI-GS for groups with higher occupational stress tended to increase, with more depressive moods and with lower QOL, and the difference in the mean score was statistically significant in all groups (Table 5-7). In all factors, when male and female were compared in the same group, female tended to have higher mean scores in exhaustion and cynicism and lower scores for professional efficacy than male.

When sub-scales' score of the MBI-GS were divided into quartiles, female tended toward higher scores in exhaustion and cynicism and lower scores in professional efficacy than male. When the mean of MBI-GS according to sex was compared previously (Table 8), female showed higher scores in all individual sub-scales than male. Referring to the quartiles presented in this study, not only can we check the burnout level of workers when checking MBI-GS results of any worker, but also check the degree of contribution of a specific subscale to burnout, helping to identify the main cause of burnout.

There are some limitations to this study. First, there are no questions on income and education level in the survey. Therefore, we could not obtain information about burnout according to income and education level in this study group. Second, the occupational distribution of the subjects is not wide-ranging enough. Although all of the study participants' jobs belonged to the category of MBI-GS, $64 \%$ of all participants belonged to the category of elementary workers. Finally, even though the geographical location of the workplace is different, essentially the workers belong to the same company. Job demands, interpersonal conflicts, organizational climate, etc., may be different for each workplace, but reward, organizational system, and job insecurity may be similar because they belong to the same company. Despite these limitations, this study is meaningful in that it presents the characteristics of MBI-GS according to the demographic factors and occupational factors for large-scale population in Korea. Furthermore, we used 3 factors to verify the concurrent validity, and, in particular, the merit of our study is that we used the job stress measurement tool developed in Korea to truly reflect the actual situation of job stress in Korea.

In order to overcome these limitations, additional surveys and research on MBI-GS will be needed for a wider range of occupations and for subjects belonging to different companies. In addition, as we have seen in this study, further studies are required to identify the reason for differences between the MBI-GS scores in Korea and those of other countries and to 
find out what kind of impacts those differences have on organizations and individuals. It is also important to examine the costs incurred by burnout; recognize the seriousness of the matter; and investigate further which sub-scale of burnout requires interventions, what kind of interventions are required to resolve the issues, and whether those interventions make real differences according to survey results.

\section{REFERENCES}

1. Meaning of burnout from Longman Dictionary of Contemporary English. https://www.ldoceonline.com/ dictionary/burnout. Accessed 11 Mar 2019.

2. Maslach C, Jackson SE, Leiter MP, Schaufeli WB, Schwab RL. Maslach burnout inventory. Palo Alto: Consulting Psychologists Press; 1986.

3. Maslach C, Schaufeli WB, Leiter MP. Job burnout. Annu Rev Psychol 2001;52:397-422. PUBMED | CROSSREF

4. Schaufeli WB. Past performance and future perspectives of burnout research. SA J Ind Psychol 2003;29(4):1-15. CROSSREF

5. Cordes CL, Dougherty TW. A review and an integration of research on job burnout. Acad Manage Rev 1993;18(4):621-56. CROSSREF

6. Halbesleben JR, Bowler WM. Emotional exhaustion and job performance: the mediating role of motivation. J Appl Psychol 2007;92(1):93-106.

PUBMED | CROSSREF

7. Maslach C. What have we learned about burnout and health? Psychol Health 2001;16(5):607-11. PUBMED | CROSSREF

8. Wright TA, Cropanzano R. Emotional exhaustion as a predictor of job performance and voluntary turnover. J Appl Psychol 1998;83(3):486-93. PUBMED | CROSSREF

9. Ahola K, Honkonen T, Kivimäki M, Virtanen M, Isometsä E, Aromaa A, et al. Contribution of burnout to the association between job strain and depression: the health 2000 study. J Occup Environ Med 2006;48(10):1023-30. PUBMED | CROSSREF

10. Bianchi R, Boffy C, Hingray C, Truchot D, Laurent E. Comparative symptomatology of burnout and depression. J Health Psychol 2013;18(6):782-7. PUBMED | CROSSREF

11. Choi HY. Burnout and health status among general employees. Asia Pac J Multimed Serv Converg Art Humanit Sociol 2015;5(3):143-53. PUBMED | CROSSREF

12. Takai M, Takahashi M, Iwamitsu Y, Ando N, Okazaki S, Nakajima K, et al. The experience of burnout among home caregivers of patients with dementia: relations to depression and quality of life. Arch Gerontol Geriatr 2009;49(1):e1-5. PUBMED | CROSSREF

13. Sandström A, Rhodin IN, Lundberg M, Olsson T, Nyberg L. Impaired cognitive performance in patients with chronic burnout syndrome. Biol Psychol 2005;69(3):271-9. PUBMED | CROSSREF

14. Kim H, Ji J, Kao D. Burnout and physical health among social workers: a three-year longitudinal study. Soc Work 2011;56(3):258-68.

PUBMED | CROSSREF

15. Gorter RC, Eijkman MA, Hoogstraten J. Burnout and health among Dutch dentists. Eur J Oral Sci 2000;108(4):261-7. PUBMED | CROSSREF

16. Halford C, Anderzén I, Arnetz B. Endocrine measures of stress and self-rated health: a longitudinal study. J Psychosom Res 2003;55(4):317-20. PUBMED | CROSSREF

17. Shirom A. Employee burnout and health: current knowledge and future research paths. Houdmont J, Leka S. In: Contemporary occupational health psychology: global perspectives on research and practice. Vol. 1. New York: John Wiley \& Sons; 2010. p.59-76. 
18. Toker S, Melamed S, Berliner S, Zeltser D, Shapira I. Burnout and risk of coronary heart disease: a prospective study of 8838 employees. Psychosom Med 2012;74(8):840-7. PUBMED | CROSSREF

19. Frone MR. Predictors of overall and on-the-job substance use among young workers. J Occup Health Psychol 2003;8(1):39-54.

PUBMED | CROSSREF

20. Enders F, West CP, Dyrbye L, Shanafelt TD, Satele D, Sloan J. Burnout and quality of life among healthcare research faculty. Res Manag Rev 2015;20:92-104.

21. Schutte N, Toppinen S, Kalimo R, Schaufeli W. The factorial validity of the Maslach Burnout InventoryGeneral Survey (MBI-GS) across occupational groups and nations. J Occup Organ Psychol 2000;73(1):53-66. CROSSREF

22. Shin KH. The validity study on Maslach Burnout Inventory-General Survey (MBI-GS). Korean J Ind Organ Psychol 2003;16(3):1-17. CROSSREF

23. Schaufeli WB, Van Dierendonck D. A cautionary note about the cross-national and clinical validity of cutoff points for the Maslach Burnout Inventory. Psychol Rep 1995;76(3 Pt 2):1083-90. PUBMED | CROSSREF

24. Ceslowitz SB. Burnout and coping strategies among hospital staff nurses. J Adv Nurs 1989;14(7):553-7. PUBMED | CROSSREF

25. Dolan N. The relationship between burnout and job satisfaction in nurses. J Adv Nurs 1987;12(1):3-12. PUBMED | CROSSREF

26. Firth H, Britton P. 'Burnout', absence and turnover amongst British nursing staff. J Occup Psychol 1989;62(1):55-9. CROSSREF

27. Schaufeli WB, Janczur B. Burnout among nurses: a Polish-Dutch comparison. J Cross Cult Psychol 1994;25(1):95-113. CROSSREF

28. Chang SJ, Koh SB, Kang D, Kim SA, Kang MG, Lee CG, et al. Developing an occupational stress scale for Korean employees. 2005;17(4):297-317. CROSSREF

29. Kroenke K, Spitzer RL. The PHQ-9: a new depression diagnostic and severity measure. Psychiatr Ann 2002;32(9):509-15. CROSSREF

30. Choi HS, Choi JH, Park KH, Joo KJ, Ga H, Ko HJ, et al. Standardization of the Korean version of Patient Health Questionnaire-9 as a screening instrument for major depressive disorder. J Korean Acad Fam Med 2007;28(2):114-9. CROSSREF

31. World Health Organization. WHOQOL-BREF: introduction, administration, scoring and generic version of the assessment: field trial version, December 1996. Geneva: World Health Organization; 1996.

32. Min SK, Lee CI, Kim KI, Suh SY, Kim DK. Development of Korean version of WHO Quality Of Life Scale Abbreviated version (WHOQOL-BREF). J Korean Neuropsychiatr Assoc 2000;39(3):517-9. CROSSREF

33. Korea Health Promotion Institution. 2017 Korean version of Alcohol Use Disorder Identification Test. https://www.khealth.or.kr/board/view?pageNum=5\&rowCnt=8\&menuId=MENU00664\&maxIndex= $99999999999999 \& \operatorname{minIndex}=99999999999999 \&$ schType=0\&schText=\&categoryId=\&continent= \&country=\&upDown=0\&boardStyle=Gallery\&no1=13\&linkId=24676. Accessed 6 Sep 2019.

34. Statistics Classification Portal. Korean Standard Classification of Occupations (KSCO). http://kssc.kostat. go.kr/ksscNew_web/link.do?gubun=002\#. Accessed 11 Mar 2019.

35. Organization for Economic Co-operation and Development (OECD). Employment rate (indicator). https://data.oecd.org/emp/employment-rate.htm. Accessed 18 Mar 2019.

36. Organization for Economic Co-operation and Development (OECD). Gender wage gap (indicator). https://data.oecd.org/earnwage/gender-wage-gap.htm. Accessed 18 Mar 2019.

37. Korean Statistical Information Service. Years of promotion. http://kosis.kr/statHtml/statHtml. do?orgId=389\&tblId=DT_389_2013_038\&conn_path=I2. Accessed 18 Mar 2019.

38. Day AL, Livingstone HA. Gender differences in perceptions of stressors and utilization of social support among university students. Can J Behav Sci 2003;35(2):73-83.

CROSSREF 
39. Aroian KJ, Norris AE, de Chávez Fernández MA, Averasturi LM. Gender differences in psychological distress among Latin American immigrants to the Canary Islands. Sex Roles 2008;59(1-2):107-18. CROSSREF

40. Herrero SG, Saldaña MÁ, Rodriguez JG, Ritzel DO. Influence of task demands on occupational stress: gender differences. J Safety Res 2012;43(5-6):365-74.

PUBMED | CROSSREF

41. Richardsen AM, Martinussen M. Factorial validity and consistency of the MBI-GS across occupational groups in Norway. Int J Stress Manag 2005;12(3):289-97. CROSSREF

42. Xanthopoulou D, Bakker AB, Kantas A, Demerouti E. Measuring burnout and work engagement: factor structure, invariance, and latent mean differences across Greece and the Netherlands. Int J Bus Sci App Manag 2012;7(2):40-52. CROSSREF

43. Ge C, Fu J, Chang Y, Wang L. Factors associated with job satisfaction among Chinese community health workers: a cross-sectional study. BMC Public Health 2011;11(1):884. PUBMED | CROSSREF

44. Wu S, Zhu W, Wang Z, Wang M, Lan Y. Relationship between burnout and occupational stress among nurses in China. J Adv Nurs 2007;59(3):233-9. PUBMED | CROSSREF

45. Rothmann S. Job satisfaction, occupational stress, burnout and work engagement as components of work-related wellbeing. SA J Ind Psychol 2008;34(3):11-6. CROSSREF

46. Valente MD, Wang YP, Menezes PR. Structural validity of the Maslach Burnout Inventory and influence of depressive symptoms in banking workplace: Unfastening the occupational conundrum. Psychiatry Res 2018;267:168-74. PUBMED | CROSSREF

47. Tselebis A, Moulou A, Ilias I. Burnout versus depression and sense of coherence: study of Greek nursing staff. Nurs Health Sci 2001;3(2):69-71. PUBMED | CROSSREF

48. Melchers MC, Plieger T, Meermann R, Reuter M. Differentiating burnout from depression: personality matters! Front Psychiatry 2015;6:113. PUBMED | CROSSREF

49. Aytekin A, Yilmaz F, Kuguoglu S. Burnout levels in neonatal intensive care nurses and its effects on their quality of life. Aust J Adv Nurs 2013;31(2):39-47. PUBMED | CROSSREF

50. Wu SY, Li HY, Tian J, Zhu W, Li J, Wang XR. Health-related quality of life and its main related factors among nurses in China. 2011:49(2):158-65.

PUBMED | CROSSREF 